\title{
The Macro Effect Of Foreign Capital And Aid On The Economic Growth In Malaysia
}

Caroline Geetha, (E-mail: bgeeth@hotmail.com), University of Malaysia Sabah

\begin{abstract}
Economic interdependence among nations of the world has become important and enormously complex. Foreign capital and aid is an important form of economic interdependence because they are the main components of capital formation especially for the developing nation. A significant amount of foreign capital and aid which has amounted to around $\$ 30$ billion of the world's gross domestic product, grows at an annual rate of 15 percent (higher than the economic growth rate of certain nation). Multinational corporations in search for profits in the developing nation undertake inflow and outflow of foreign capital in the form of foreign direct investment, skills and technology. This creates internal economies of scale for the parent company and external economies of scale for its subsidiaries. Overwhelming performance of foreign capital can also create external diseconomies of scale known as "stunting effects" for the developing nation. The government of the developed countries for political and humanitarian reasons also offers foreign aid. Foreign aid should be paired well with the stages of the economic development of a country to create increasing returns. This paper provides a critical analysis of growth in relation to foreign capital and aid in Malaysia. The analysis is divided into two sections. The first section looks at foreign capital and aid as an independent variable while the second section looks at foreign capital and aid as the dependent variable. Foreign capital is found to be positively correlated to economic growth and it is also highly significant compared to foreign aid which has no positive correlation and hardly contributes to Malaysia's economic growth. Finally some policy options are recommended to improve the economic growth in Malaysia.
\end{abstract}

\section{Introduction}

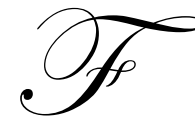

oreign capital and aid has contributed as much as $\$ 30$ billion of the world's gross domestic product and it grows at the rate of 15 percent annually (higher than the growth rate of certain nation). Multinational corporations in search of profits are responsible in directing inflow and outflow of foreign capital. The foreign capital undertaken by the private firms are usually in the form of foreign direct investment, technology and skills. An overview of multinational corporations is desirable because they can control a significant amount of foreign direct investment. A multinational firm is a chain of firms operating under national sovereignties. The multinationals regard nation states as sales territories. They view beyond boundaries with profit objective. They shift their resources or look for better resources to expand their opportunities. According to Kotler, when a product reaches the maturity stage in its life cycle, foreign direct investment takes place in order to shift the production process to places which has lower cost of production to be competitive. Krasko and Tairo (1974) consider states as sales territories and boundaries are impediments of profit objective that should be eliminated. To the global perspective, the government of the nation is more concern with the activity of the firm within the boundary but the host branches or subsidiaries are at their disadvantage because they cannot bargain with the firms which move its resources else where for survival or favorable business environment. Thus the nation states will emphasize nationalism while the subsidiaries will stress on profit.

Readers with comments or questions are encouraged to contact the authors via email. 
Foreign capital in the form of foreign direct investment grew rapidly over the past 20 years or so, especially in the developing nation (Refer to Table 1).

Table 1

Foreign Direct Investment in all developing nations (billion US)

\begin{tabular}{|l|c|c|c|c|c|c|c|c|c|c|}
\hline Year & 1973 & 1974 & 1975 & 1976 & 1977 & 1978 & 1979 & 1980 & 1981 & 1982 \\
\hline FDI & $\mathbf{4 . 4}$ & $\mathbf{4 . 5}$ & $\mathbf{6 . 1}$ & $\mathbf{1 . 9}$ & $\mathbf{4 . 5}$ & $\mathbf{7 . 0}$ & $\mathbf{8 . 3}$ & $\mathbf{3 . 7}$ & $\mathbf{1 7 . 6}$ & $\mathbf{1 9 . 8}$ \\
\hline Year & 1983 & 1984 & 1985 & 1986 & 1987 & 1988 & 1989 & 1990 & 1991 & 1992 \\
\hline FDI & $\mathbf{1 3 . 5}$ & $\mathbf{1 3 . 5}$ & $\mathbf{1 0 . 5}$ & $\mathbf{1 0 . 2}$ & $\mathbf{1 4 . 4}$ & $\mathbf{1 6 . 7}$ & $\mathbf{1 6 . 7}$ & $\mathbf{1 9 . 3}$ & $\mathbf{2 5 . 2}$ & $\mathbf{3 0 . 1}$ \\
\hline
\end{tabular}

Sources: Yin, Xiangkang. 1999. Foreign direct investment and industry structure. Journal of Economic Studies, Vol.: 26, Issue 1. Pp. 22.

The introduction of foreign direct investment, technology and skills by the multinationals will enable parent company to experience internal economies of scale while its subsidiaries will face spill over effects known as external economies of scale. Of course, the efficiency of foreign firms can also create external diseconomies known as "stunting effects" or "intergenerational negative spillover effects" for the developing nation. Indigenous firms will find themselves competing with foreign firms who enjoys better in terms of technology, new equipment and greater capital in the same market. This is known as the "American Challenge" where the overwhelming performance of entrepreneurs will create monopolistic power. The foreign entrepreneurs are able to recover profits in the short-term period but would greatly effect the less developed nations economic structure. Bandera (1968) found that overconcentration of foreign capital and dependency of skilled (personnel) on the availability and favors of the foreign capital seemed to have discouraged local entrepreneurs in Poland.

The theory of polarization in the Less Developed Nation also stress that foreign investors with advanced technology and large funds would control the more sophisticated and dynamic industries while the local businessman are more traditional and less sophisticated. Peter (1971) voices his skepticism that private foreign investment can create income inequalities due to wage differential. The urban areas will experience high wage compared to the rural areas. In the long run this may lead to serious social unrest and political instability in the host country.

Foreign aid is also a form of capital interdependency that have been expanded and perpetuated for political and humanitarian reasons for the last 40 years. Since 1946, the United States has given over US $\$ 146$ billion in humanitarian assistance to foreign countries. In 1985, non-military aid worth US \$10 billion ranging from free food to balance of payment support to project assistance and population planning program were provided. A study conducted by Burnside and Dollar (2000) showed that foreign aid has no impact on growth in countries with poor macroeconomic policies while it leads to faster growth in countries with good policies. World Bank (1992) states financial aid works in a good policy environment [and therefore] financial assistance should be targeted more effectively to low-income countries with sound economic management.

Recent studies on traditional view claims that foreign aid does not only effect countries with poor macroeconomic management but also creates a negative correlation with domestic savings behavior. Griffin and Enos (1970) set the rates of growth of gross national product against the ratio of "aid" for twelve Latin American countries for the period of 1957 to 1964 and found that the two variables are inversely correlated. Krasko and Tairo (1974) found that the relationship between foreign direct investment and economic growth is different compared to foreign aid and economic growth. Foreign direct investment is correlated with economic growth with a highly significant correlation coefficient of 0.66 . The logic behind the value is that the economies hosting larger amount of foreign direct investment tend to grow faster than those hosting smaller amount of such investment do. Moreover, foreign capital is directed more towards countries with higher economic growth. Further research conducted by Hansen and Tarp (2000) and Burnside and Dollar (2000) revealed that when foreign aid and economic growth are paired in a country with poor economic policy, it creates decreasing returns. Foreign aid that is used to finance project should be complemented with the stages of economic development in a country.

High correlation between foreign direct investment and economic growth and no correlation between for- 
eign aid and economic growth can conclude that foreign direct investment are more directed to economic rationality of good returns to investment and foreign aid should be directed to investment that can increase economic growth and standard of living.

\section{Objective}

The overall objective of this paper is to provide a critical analysis between foreign capital and aid towards economic growth in Malaysia from 1970 to 2000.

The specific objectives of this paper are as follows:

a) To determine whether foreign capital is the main determinant of economic growth in Malaysia.

b) To determine whether foreign aid contributes to the economic growth in Malaysia.

c) Finally to identify other contributing variables and to give some policy options in improving the economic growth in Malaysia.

\section{Methodology}

Miller and Van Hoose (2001) claims that economic growth does not only measure increase in the real output but also the changes of growth in percapita real GDP. Economic growth is always desirable as long as the expected benefit can outweigh the cost. Based on the classical and traditional macroeconomic theory the key factors that can determine economic growth are the growth in labor force and the capital formation, the long run aggregate production function is written as $\mathrm{Y}=\mathrm{f}(\mathrm{N}, \mathrm{K}) \mathrm{x} A$, where $\mathrm{Y}$ is output, $\mathrm{N}$ is the labor force, $\mathrm{K}$ is capital and $\mathrm{A}$ is the improvement in the level of technology which can increase the productivity of capital and labor. The key factors that can influence the amount of services the labor can supply are real wage, government policies (tax cuts), immigration followed by political freedom and economical freedom in the country. Capital investment is a component of demand for loanable funds and savings is a component of supply of loanable funds. The interaction between the demand and the supply curve creates real interest rate. Real interest rate is a tool used to decide whether labor should be substituted with capital in the process of production. However capital and labor can also be considered as complements in certain environment. To the extent that there are economies of scale in the production process, meaning the average production cost can be saved due to increase in the size of the firm's operations by expanding simultaneously the use of capital and labor. Hence it can be concluded that economic growth can be related to capital formation, increase in labor force, increase in productivity and finally the quality of the factors of production. Both foreign direct investment and foreign aid are the components of economic growth because they are one of the sources of capital formation. Thus,

Economic growth $=\mathrm{f}$ (domestic capital formation, foreign direct investment, foreign aid, increase in labor force and other variables)

Each factors are expressed in the form of ratio to gross domestic product or a percentage to gross domestic product where $\mathrm{Y}$ is the common denominator as gross domestic product, $\mathrm{I}$ is the symbol for capital formation where if it is accompanied with $\mathrm{d}$ becomes domestic investment and $\mathrm{f}$ is foreign direct investment.

Kraska and Taira (1974) found two ways in exploring statistically the relationship between economic growth with foreign direct investment and economic growth with foreign aid. One is by looking at foreign direct investment and foreign aid as an independent variable and the other as the dependent variable. How much the independent variable is able to explain the dependent variable can be seen with the value of coefficient of determination $\left(R^{2}\right)$ and the significance of the t-test.

Growth equation (3.1) to (3.9) presented shows that the independent variables chosen to reflect economic growth $(\Delta y / y)$ are domestic capital formation $\left(I_{d}\right)$, changes in labor force $(\Delta \mathrm{L})$, foreign direct investment $\left(\mathrm{I}_{\mathrm{f}}\right)$, foreign aid (FA) and crude death rate (D). The parameters of all the variables are expected to have a positive relationship with economic growth except for crude death rate. 
Economic growth equations where the foreign direct investment and the foreign aid are placed as the independent variable are as follows:

$$
\begin{array}{ll}
\Delta y / y & =\alpha_{0}+\alpha_{1} I_{d}+\mu \\
\Delta y / y & =\beta_{0}+\beta_{1} \Delta \mathrm{L}+\mu \\
\Delta y / y & =\chi_{0}+\chi_{1} I_{d}+\chi_{2} \Delta \mathrm{L}+\mu \\
\Delta y / y & =\delta_{0}+\delta_{1} I_{d}+\delta_{2} I_{f}+\delta_{3} \Delta L+\mu \\
\Delta y / y & =\lambda_{0}+\lambda_{1} I_{d}+\lambda_{2} I_{f}+\lambda_{3} \Delta L+\lambda_{4} D+\mu \\
\Delta y / y & =\rho_{0}+\rho_{1} I_{d}+\rho_{2} \Delta L+\rho_{3} D+\mu \\
\Delta y / y & =\sigma_{0}+\sigma_{1} I_{d}+\sigma_{2} F A+\sigma_{3} \Delta L+\mu \\
\Delta y / y & =\tau_{0}+\tau_{1} I_{d}+\tau_{2} I_{f}+\tau_{3} F A+\tau_{4}+\Delta L+\mu \\
\Delta y / y & =\omega_{0}+\omega_{1} I_{d}+\omega_{2} I_{f}+\omega_{3} F A+\omega_{4} \Delta L+\omega_{5} D+\mu
\end{array}
$$

The second section of the analysis looks at foreign direct investment and foreign aid as the dependent variable and all other factors as the independent variable. According to Krasko and Tairo (1974), investors will only invest in nation with strong economic fundamental, therefore foreign direct investment was identified as the dependent variable while the economic growth, foreign aid, domestic capital formation and increase in labor force was the independent variable. Again the coefficient of determination $\left(\mathrm{R}^{2}\right)$ will be able to explain how much the changes in the dependent variable can be determined by the independent variable and the $T$ test will determine the significance of the parameter at 99 percent, 95 percent and 90 percent confidence level. The economic models formed are as follows:

$$
\begin{array}{ll}
\mathrm{I}_{\mathrm{f}} & =\alpha_{0}+\alpha_{1} \Delta \mathrm{y} / \mathrm{y}+\mu \\
\mathrm{I}_{\mathrm{f}} & =\beta_{0}+\beta_{1} \Delta \mathrm{y} / \mathrm{y}+\beta_{2} \mathrm{FA}+\mu \\
\mathrm{I}_{\mathrm{f}} & =\delta_{0}+\delta_{1} \Delta \mathrm{y} / \mathrm{y}+\delta_{2} \mathrm{I}_{\mathrm{d}}+\mu \\
\mathrm{I}_{\mathrm{f}} & =v_{0}+v_{1} \Delta \mathrm{y} / \mathrm{y}+v_{2} \Delta \mathrm{L}+\mu
\end{array}
$$

The parameters for all the variables from equation (3.10) to (3.12) are expected to have a positive relationship with foreign direct investment.

\section{Results}

Table 2 presents some of the essential statistical results of the growth function (3.1) to (3.9) mentioned above. Equation (3.1) and (3.2) indicates that domestic capital formation alone explains 38 percent of economic growth, while increase in labor force by itself explains 63 per cent of such variation. Both domestic capital formation and changes in the labor supplies are found to be significant at 99 percent. 
Table 2

\begin{tabular}{|c|c|c|c|c|c|c|c|}
\hline Equation & Constant & $\mathbf{I}_{\mathbf{D}}$ & $\mathbf{L}$ & FDI & D & FA & $\mathbf{R}^{2}$ \\
\hline 3.1 & $\begin{array}{l}-2.705 \\
(-1.923) \\
\end{array}$ & $\begin{array}{l}18.196 \\
(4.22) \\
\end{array}$ & & & & & 0.38 \\
\hline 3.2 & $\begin{array}{l}-4.793 \\
(-4.146) \\
\end{array}$ & & $\begin{array}{l}1.2 \mathrm{E}-02 \\
(6.986)\end{array}$ & & & & 0.63 \\
\hline 3.3 & $\begin{array}{l}-5.523 \\
(-4.540)\end{array}$ & $\begin{array}{l}6.490 \\
(1.59)\end{array}$ & $\begin{array}{l}1.04 \mathrm{E}-02 \\
(4.77)\end{array}$ & & & & 0.66 \\
\hline 3.4 & $\begin{array}{l}-5.663 \\
(-7.194)\end{array}$ & $\begin{array}{l}1.981 \\
(0.923)\end{array}$ & $\begin{array}{l}1.259 \mathrm{E}-03 \\
(9.866)\end{array}$ & $\begin{array}{l}\text { 7.796E-05 } \\
(1.762)\end{array}$ & & & 0.93 \\
\hline 3.5 & $\begin{array}{l}-16.515 \\
(-6.808) \\
\end{array}$ & $\begin{array}{l}4.735 \\
(2.759)\end{array}$ & $\begin{array}{l}1.906 \mathrm{E}-03 \\
(11.223)\end{array}$ & $\begin{array}{l}1.356 \mathrm{E}-05 \\
(1.337)\end{array}$ & $\begin{array}{l}1.209 \\
(4.612)\end{array}$ & & 0.96 \\
\hline 3.6 & $\begin{array}{l}-9.844 \\
(-1.638) \\
\end{array}$ & $\begin{array}{l}7.061 \\
(1.688) \\
\end{array}$ & $\begin{array}{l}1.26 \mathrm{E}-03 \\
(3.376)\end{array}$ & & $\begin{array}{l}0.525 \\
(0.734) \\
\end{array}$ & & 0.67 \\
\hline 3.7 & $\begin{array}{l}-5.530 \\
(-3.833) \\
\end{array}$ & $\begin{array}{l}6.487 \\
(1.556) \\
\end{array}$ & $\begin{array}{l}1.041 \mathrm{E}-03 \\
(3.758)\end{array}$ & & & $\begin{array}{l}1.578 \mathrm{E}-06 \\
(0.009)\end{array}$ & 0.66 \\
\hline 3.8 & $\begin{array}{l}-4.972 \\
(-7.017) \\
\end{array}$ & $\begin{array}{l}2.537 \\
(1.372) \\
\end{array}$ & $\begin{array}{l}1.07 \mathrm{E}-05 \\
(9.107)\end{array}$ & $\begin{array}{l}\text { 6.559E-05 } \\
(1.720)\end{array}$ & & $\begin{array}{l}2.13 \mathrm{E}-04 \\
(3.217)\end{array}$ & 0.95 \\
\hline 3.9 & $\begin{array}{l}-14.050 \\
(-4.861) \\
\end{array}$ & $\begin{array}{l}4.451 \\
(2.638) \\
\end{array}$ & $\begin{array}{l}1.703 \mathrm{E}-03 \\
(7.927)\end{array}$ & $\begin{array}{l}2.051 \mathrm{E}-05 \\
(1.579)\end{array}$ & $\begin{array}{l}0.970 \\
(3.212) \\
\end{array}$ & $\begin{array}{l}\text { 9.92E-05 } \\
(1.489)\end{array}$ & 0.97 \\
\hline
\end{tabular}

According to equation (3.3), more than half of the economic growth in Malaysia is explained jointly by domestic capital formation and increases in labor force. Domestic capital formation is significant at 99 percent and changes in labor supplies are significant at 80 percent. By adding foreign direct investment as one more explanatory variable, the explanation of increases in economic growth is indicated by the rise in R-square from 66 percent to 93 percent. Table 2 shows that the proportion "explained" improves as one moves from equation (3.1) or (3.2) to (3.3) and thence to (3.4), adding one more variable as one goes. Foreign direct investment is significant in explaining changes in economic growth at 90 percent confidence level.

We now add one more variable that is considered relevant to economic growth via its possible effect on the improvement of the quality of labor, i.e., the decline in the crude death rate. The proportion explained economic growth rises to 96 percent. The regression coefficient also meets the usual standard of significance at least at 99 percent. It is also interesting to find that the significance of the coefficient for increase in the supply of labor force in equation (3.5) is high, in contrast with all other equations from (3.1) to (3.4). This probably means that as other variables take up their shares of "explanation" for economic growth, the relationship between changes in labor force and economic growth become more sharply defined than formerly.

The significance level for foreign direct investment varies from 80 percent to 90 percent. Hence its contribution to the "explanation" in the difference of economic growth may be seen by comparing equation with and without it, other things remaining the same, such as Equation (3.3) and (3.4), equation (3.5) and (3.6) and finally equation (3.7) and (3.8). The R-square rises from 66 percent to 93 percent with foreign direct investment between equation (3.3) and (3.4). The value decreases from 96 percent to 67 percent without foreign direct investment between equation (3.5) and (3.6) and rises again from 66 percent to 95 percent with foreign direct investment between equation (3.7) to (3.8).

Equation (3.7) to (3.9) involves foreign aid. If foreign aid is not combined with foreign direct investment in explaining economic growth, the variable is found to be insignificant in explaining changes in economic growth. The variable is found to be significant in equation (3.8) and (3.9) when combined with foreign direct investment.

Finally, equation (3.9) uses all the variables simultaneously; the variables that survive at least 95 per cent significant level are domestic capital formation, changes in the labor supply, and crude death rate. Moreover throughout the computation, increase in the labor force has the highest probability level, followed by domestic capital formation and foreign direct investment and lastly foreign aid. 
Whether this means anything on the theoretical grounds is questionable, but it may be a permissible statement say that economic growth in Malaysia are reasonably explained by concurrent differences in changes in labor supply complemented with the quality of labor, domestic and foreign capital formation and finally the foreign aid.

Table 3

\begin{tabular}{|l|l|l|l|l|l|l|}
\hline Equation & Constant & Econ. Growth & Id & L & FA & $\mathbf{R}^{2}$ \\
\hline 3.10 & $8.265 \mathrm{E}-02$ & $1.140 \mathrm{E}-05$ & & & & 0.104 \\
& $(7.513)$ & $(1.832)$ & & & & \\
\hline 3.11 & $-2.32 \mathrm{E}-02$ & $1.068 \mathrm{E}-05$ & 0.338 & & & 0.355 \\
& $(-0.693)$ & $(1.986)$ & $(3.301)$ & & & \\
\hline 3.12 & $8.479 \mathrm{E}-02$ & $1.155 \mathrm{E}-05$ & & -68.732 & & $(-0.163)$ \\
& $(4.921)$ & $(1.805)$ & & & $-1.896 \mathrm{E}-06$ & 0.105 \\
& $8.473 \mathrm{E}-02$ & $1.049 \mathrm{E}-05$ & & & & \\
\hline 3.13 & $(6.831)$ & $(1.552)$ & & & & \\
& & & & & & \\
\end{tabular}

Equation (3.10) in Table 3 suggests that economic growth alone explains about 10.4 percent in hosting foreign direct investment in Malaysia. Of other variables that can be combined with foreign direct investment, only domestic capital formation is found statistically significant in explaining changes in foreign direct investment and the value of R-square rises to 35.5 percent. Foreign aid and changes in the labor supplies is insignificant in explaining changes in foreign direct investment.

This is understandable because domestic capital formation is included in the creation of social overhead capital and residential construction, which is found to be necessary in making direct production profitable. Foreign direct investment goes directly into the production process in search of profit. In addition the reasonable efficiency of foreign direct investment as an explanatory variable in the rate of economic growth as ascertained by Table 2 might also indicate that foreign direct investment is attracted in greater amount by fast growing countries than the slow growing ones. Table 3 shows that the foreign direct investment does not respond to changes in the foreign aid and changes in the labor force but towards domestic capital formation. It is because social overhead capital built from the domestic capital formation can be expanded for further economic activities directly related to the market can be profitably carried on through foreign direct investment.

\section{Conclusion}

In this study there are two basic principles to be concluded: First, changes in the labor supplies are the main determinant of economic growth in Malaysia. Domestic capital formation provides social overhead capital and residential construction, which acts as base and creates and environment to expand profitable production. This creates economic growth. Foreign direct investment comes in search for profit where the economic growth is high. The second principle is comforting when economic reasoning alone fails to account for the direction and the volume of foreign aid. This is because foreign aid is predominantly political.

\section{Policy Option}

The critical analysis on foreign direct investment and foreign aid in relation to economic growth has increased the knowledge on the main factors that stimulate economic growth and yield several important policy lessons. The main factor that contributes to the economic growth in Malaysia is the changes in the supply of labor force. In today's business world where the pace keeps on going faster and decisions are more complex; labor force cannot waste time on management mistakes. They need to be faster, better and smarter in what they do ever before. This heavily relies on how people are recruited, trained, managed and motivated.

Selecting the right individual is vital and the financial losses from bad selection can be avoided. To avoid costly mistakes, certain factors should be identified. These factors are behaviors necessary to perform the job according to an organization culture. Skills, competencies and core values are some of the factors to be considered. 
After appropriate selection process are made, the personnel should be complemented with some direction and training. This will help in creating a versatile state labor force.

A thorough skill analysis of individuals potential and the potential skills required to take a particular role will create a comprehensive plan in training and development. Traditionally, training is conducted out or in the office, away from work. When laborers are being sent for training, work normally comes to a halt. This is not the case with new information and communication technology (ICT).

With the advancement of information and communication technology, individual can be trained by himself or herself at their own pace without having to leave the office. Hence the "just in time" concept can be practiced. Learning and training are done through the process of independent study and online collaboration. Resources are shared and problems can be solved in the collaborative manner. The teaching materials can be downloaded and individuals can study with minimal facilitation from trainers and lecturers.

Moreover, as talent decreases and demand increases, it would be getting increasingly hard to hold on to high performance employees. The enormous amount of time, effort and cost that goes into training the labor force can vanish if the individuals are pinched by the competitors locally or even abroad. Hence it is critical that the organization implement effective retention strategies to ensure high potential candidates to stay with the organization and their potential to be fully utilized.

The second factor that contributes to economic growth is domestic capital formation. Macroeconomic stabilization plays an important role in increasing domestic capital formation. One might think that when stabilization is achieved, it reduces precautionary savings, thereby reducing domestic capital. On the other hand, fiscal adjustment in terms of tax exemption will likely to create domestic capital that correlates positively to economic growth.

Savings mobilization program that varies according to area can be established. In some cases, the types of forced savings programs may be appropriate such as required share purchases in an organization or profit sharing directed to regular contractual savings. The key element in mobilizing funds depends on the attractiveness of the reward paid along with the services contributed. The supply of deposits should be more service elastic compared to interest elastic. No doubt interest adjustment is necessary since Malaysia is a developing nation but using interest as a tool in mobilizing deposits and collecting revenue should be done carefully because Malaysia is a nation which is sensitive towards changes in interest rates. Moreover there should also be a link between deposits and credit access in order for an individual to remain in the institutionalized financial savings. This will avoid direct interest competition but construct more convenient services for customers. It is obvious that formation of domestic capital should be looked as a marketing challenge where appropriate financial packages and technology should be designed.

Finally, foreign direct investment is an integration of institutional variables. FDI Institutional Fitness Theory suggest every nation has the opportunity to identify and expand its competitive strengths to increase its share of global foreign direct investment by attracting, absorbing and retaining FDI. The four FDI Fitness Institutions are government, market, education and socio-cultural.

\section{Increasing concentration}

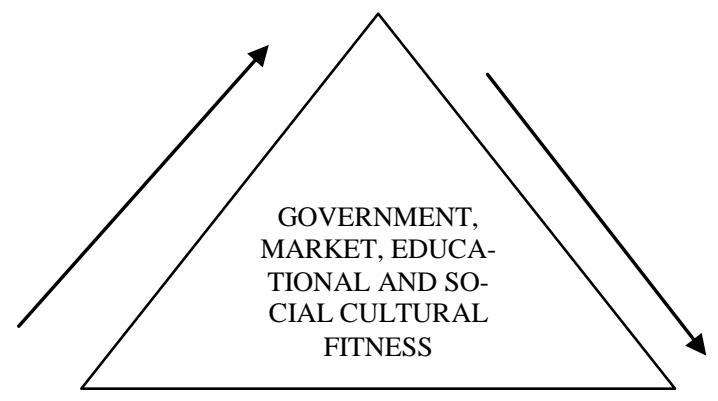

More diffusion

Source: Foreign Direct Investment and its determinants in emerging economics.

African Economic Paper. Discussion Paper 9. July 1998. 
Socio-culture is the oldest institution, complex and most diffused. It is most difficult and time consuming to change. The degree to which a society is receptive towards foreign culture depends on the level of educational attainment, exposure to foreign culture and global economic integration. The higher the degree of receptiveness enhances the nation capacity to attract FDI.

Education builds human capital and prepares them for the rapidly changing global economy. Education fitness improves the ability to process information, creativity of R\&D that prepares a fertile ground. Market is the economic and financial indicator in attracting FDI. Market fitness should be exposed to competition and with protective regulation. This is essential because it involves the cost of doing business. Government is the primary source for actions and policies in shaping FDI. Government fitness is reflected in economic openness with minimal trade and exchange rate control. It also means strong rule of law such as corruption based on legal and administrative transparency and equity. Some countries have strong preconditions in their favor but investors will come anyway. This is due to large population and abundance of raw materials such as India and China.

\section{References}

1. Bovard, James. 1986. Policy Analysis: The Continuing Failure of Foreign Aid, Wall Street Journal, and Chicago Tribune.

2. Gorg, Holger. 2000. Analyzing foreign market entry: The choice between Greenfield investment and acquisitions. Journal of Economic Studies:Vol.27, pp.165-181.

3. Wilhelms, Saskia \& Stanley, Morgan. 1998. Foreign Direct Investment and Its Determinants in Emerging Economies, African Economic Policy Paper, Discussion Paper 9.

4. Yin, Xiangkang. 1999. Foreign Direct Investment and industry structure, Journal of Economic Studies: Vol. 26, pp. 38-57.

5. Taira, Koji \& Kraska Michael. 1974. Foreign Capital, Aid and Growth in Latin America, The Development Economics: Vol.12. No.1-4.

6. Ady, P. 1971. Private Foreign Investment and the Developing World, New York Praeger Publishers.

7. Bandera, V.N. 1968. Foreign Capital as an Instrument of National Economic Policy, The Hague: M.Nijhof.

8. Griffin, K.B. \& Enos, J.L. 1970. Foreign Assistance: Objectives and Consequences, Economic Development and Cultural Change, Vol.: 18, No. 3.

9. $\quad$ World Bank. 1992. World Bank Development Report, Washington DC.

10. Kotler, Philip. 1998. Principles of Marketing, Prentice Hall.

11. Hansen, Henrik \& Dalgaard, Carl - Johan. 2000. On Aid, Growth, and Good Policies, Center for Research in Economic Development and International Trade, University of Nottingham.

12. Burnside, C. and Dollar, D. 2000Aid, policies and growth, American Economic Review. Forthcoming.

13. Hansen, H and Tarp, F. 2000. Aid and growth regressions, Journal of Development Economics. Forthcoming. 